\title{
Study and Comparison of Technologies in Home And Building Electronic Systems by Fuzzy Logic
}

\author{
R. Sáenz López ${ }^{1}$, E. Jiménez Macías ${ }^{1}$, M. Pérez de la Parte ${ }^{2}$ \\ ${ }^{1}$ Department of Electrical Engineering. ${ }^{2}$ Department of Mechanical Engineering \\ E.T.S.I.I., University of La Rioja. Luis de Ulloa, 20. 26004. Logroño (Spain) \\ Phone/Fax number: +34 941 299502, +34 941299478 \\ e-mail \{raul.saenz; emilio.jimenez\}@unirioja.es
}

\begin{abstract}
Nowadays, there exist in market many systems of automation, energy management and security for housings and buildings (domotics systems). In many occasions the engineer find difficult to decide what system to choose due to the multiple factors that have to be taken into account in the decision. This work considers the most outstanding factors for the decision taking, which constitutes the input variables of a Fuzzy model developed in order to help in that decision, where the output variables measure the grade of adaptation of the system to the home. A high number of rules are defined to develop the inference and to generate the appropriate output values. The proposed model is developed with the Fuzzy Logic Toolbox of MATLAB, and is evaluated on ten different cases, which are presented in order to show the methodology, the behaviour of the model and the results.
\end{abstract}

\section{Key words}

Home automation, fuzzy logic, electrical engineering code

\section{Introduction}

In general, automation, energy technical management, and security in housings and buildings system installations are known as domotics (word that derives from Domus -house in Latin- and Robotics), in the case of individual housings such as typical houses, or inmotic in case that the installation refers to buildings (we will refer both as domotics for simplicity).

Last February of 2007 the Spanish Government, by its Ministry of Industry, Tourism and Commerce has published inside the Technical Guide of Application of the Spanish Electrical Engineering Code of Low tension (REBT from its Spanish name "Reglamento electrotécnico de Baja Tensión”) the document GUIDEBT-51: "Installations of automation, energy technical management, and security in housings and buildings " in which the nets that compose the installation of a housing or building are defined. The following nets can be distinguished (Figure 1):

- Net of Information technologies.

- Television Net

- Phone Net

- Domotics control Net (integrated inside the electrical net).

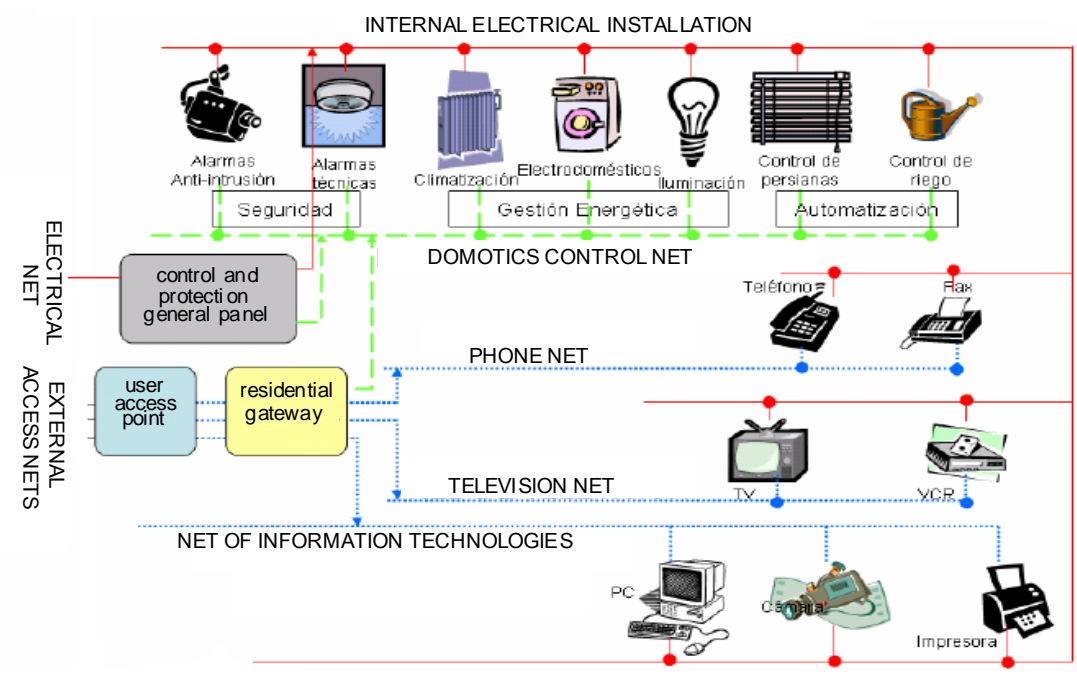

Fig. 1. Nets that compose the installation of a housing or building. 
The domotics net is regulated by the REBT in its Instruction Technique-51 (IT-51), dealing with electrical security and electromagnetic compatibility control; it should be integrated within the electrical power net and coordinated with the rest of the nets with which it is related. The mentioned net can be implemented by means of specific wire or through carrier waves coupled to the electric net.

\section{Installation possibilities}

Systems of automation, energy management and security in housings and buildings receive information coming from the input signals (sensors or controls), process it and emit orders to actuators and outputs in order to improve comfort, energy management, and people, animal, and goods safety. These systems can also have the possibility of communicating with external communication nets such as the Commuted Telefónica Net or Internet services.

For the implementation of the installation three types of architectures are admitted (Figure 2):

- Centralized: a central node holds the control functions and the control. All the entrance devices and actuators are physically wired to the node.

- Semi- Decentralized: a central node holds the control functions and control. Intermediate nodes that communicate with the central node for information transfer exist. The entrance devices and actuators are physically wired to the passing nodes.

- Decentralized: all the components share the communication line, holding each one of them some of control functions.

The REBT-IT-51 admits the ring, tree, bus and star topologies, as well as any combination of them.

The physical means admitted are:
- The conductors of the electrical net (carrier currents)

- Specific wires for the installation: twisted pair, parallel, coaxial, and optical fiber.

- Radio signals: infrared, radio frequency, ultrasounds, or systems connected to the telecommunications net.

The installation documents must include:

- User manual

- Installer manual

Two automation levels are defined, basic and normal, with functionalities and specific applications.

\section{Fuzzy model and methodology}

Diverse solutions exist in market for the development of domotics installations by using any of the tree different architectures presented: centralized, decentralized, and semi-decentralized.

A study and comparative of the different types of existent solutions in market have been developed in order to help to decide which is the most appropriate solution in each case, depending on the characteristics of the domotics installation to design and on the recommendations of the REBT-IT-51.

The methodology used to carry out the comparative of systems is based on fuzzy logic. A fuzzy model has been designed, validated, and employed, using MATLAB and its Fuzzy Logic Toolbox.

The work also includes the study and analysis of the most outstanding factors for the decision of the most suitable installation and its characteristics. As factors for the decision taking the following ones (Table 1) have been considered for buildings and semidetached houses; the input factors considered for houses are very similar (Table 2):

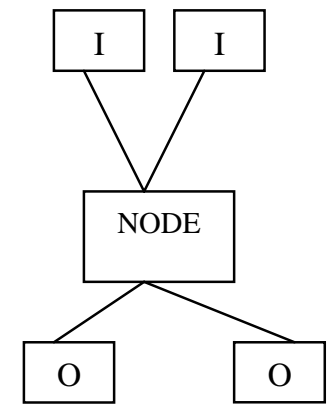

Centralized

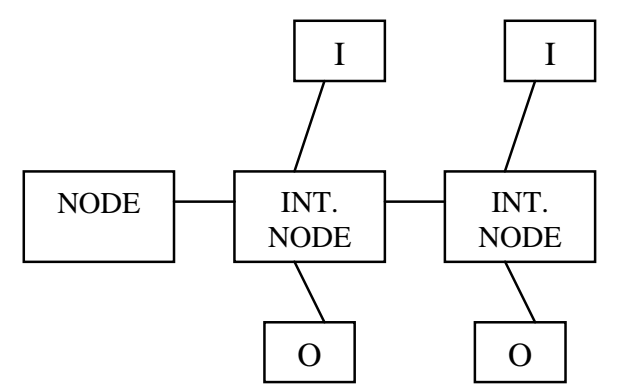

Semi-decentralized

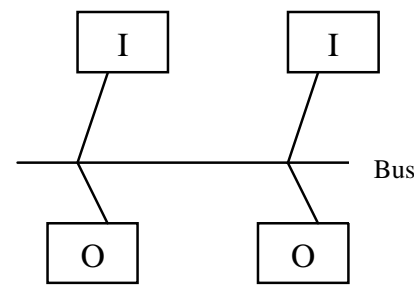

Decentralized

Fig. 2. Different architectures in the implementation of the installation 
Table 1. Factors considered for the choice of the most suitable domotics installation in buildings and semidetached houses

number of housings

number of rooms per housing

building age

number of functionalities

number of external measures

estimated cost per housing

design and planning time

implementation and start-up time

extension possibility

maintenance

user age

supervision

external control of the installation

Table 2. Factors considered for the choice of the most suitable domotics installation in houses

number of buildings

number of rooms per building

building age

number of functionalities

number of external measures

estimated cost of the building

design and planning time

implementation and start-up time

extension possibility

maintenance

user age

supervision

external control of the installation

For every input variable a domain is defined, as well as the associate membership function. For instance the variable "number of housings" has associate three gaussian membership function, named lower, half and high respectively, which is defined in the following way in Matlab (Table 3) with the result shown in Figure 3:

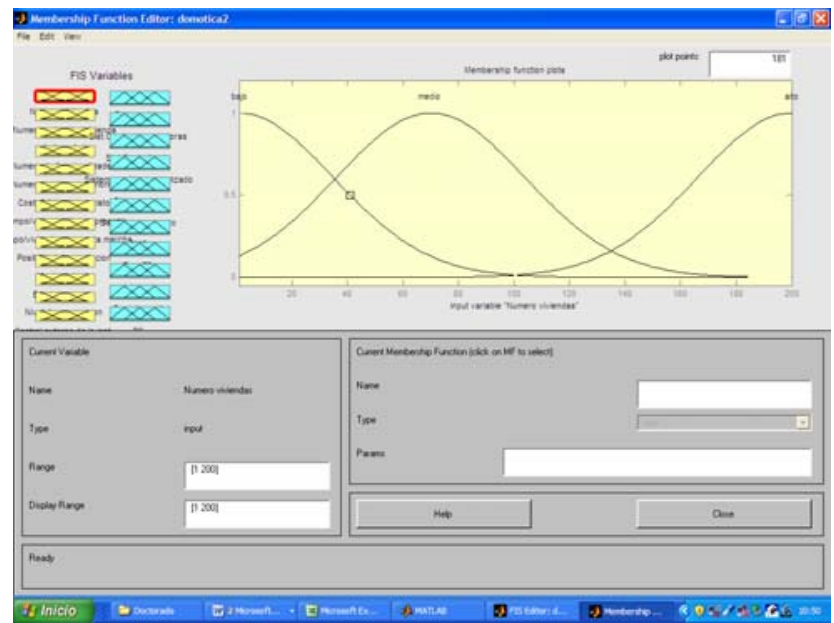

Fig. 3. Input variable "number of housings" on Matlab Fuzzy Logic Toolbox
Table 3. Definition of the three gaussian membership functions for the input variable "number of housings" [Input1]

Name $=$ 'Numero viviendas'

Range $=\left[\begin{array}{ll}1 & 200\end{array}\right]$

NumMFs $=3$

MF1='bajo':'gaussmf',[34 1]

MF2='medio':'gaussmf',[34 70]

MF3='alto':'gaussmf',[34 200]

As output variables the following ones (Table 4) are considered in both cases (buildings and houses):

Table 4. Output variables of the fuzzy application

bus system

carrier current system

centralized system

decentralized system

mixed system

preprogramable system

SMS

telephone

Internet

touchscreen

PC

In the same way the output variables are defined, as for instance the "Bus system" variable shown in table 5 and Figure 4, which has three triangular functions named "non-advised”, “advised”, and "highly advised”.

Table 5. Output variable "Bus system" on Matlab

[Output1]

Name $=$ 'Sistema bus'

Range $=\left[\begin{array}{ll}0 & 1\end{array}\right]$

NumMFs $=3$

MF1=' nonadvised ':'trimf',[-[-0.4 00.4$]$

MF2=' advised':'trimf',[0.1 0.5 0.9]

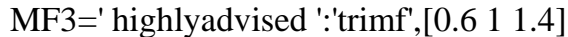

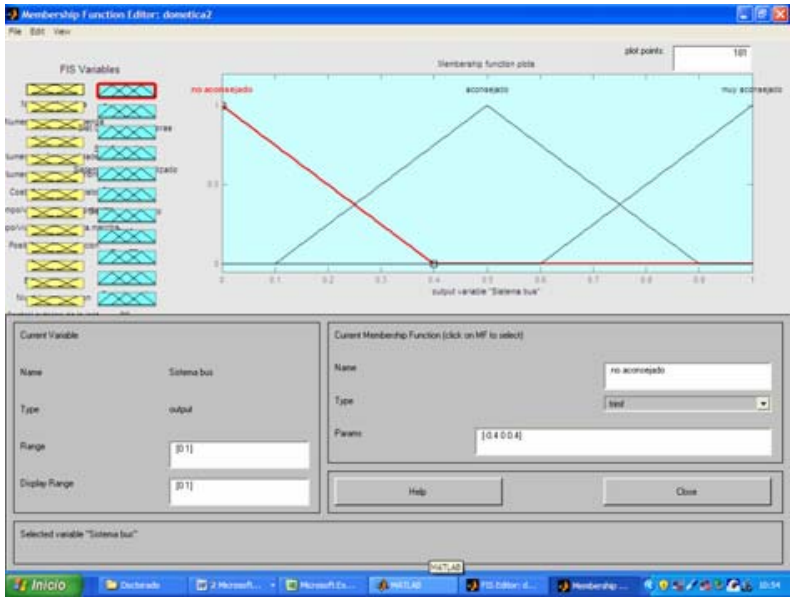

Fig. 4. Output variable "Bus system” on Matlab Fuzzy Logic Toolbox 
The relationship between the input and the output variables is implemented by a series of rules whose interpretation uses the "Mandani" method.

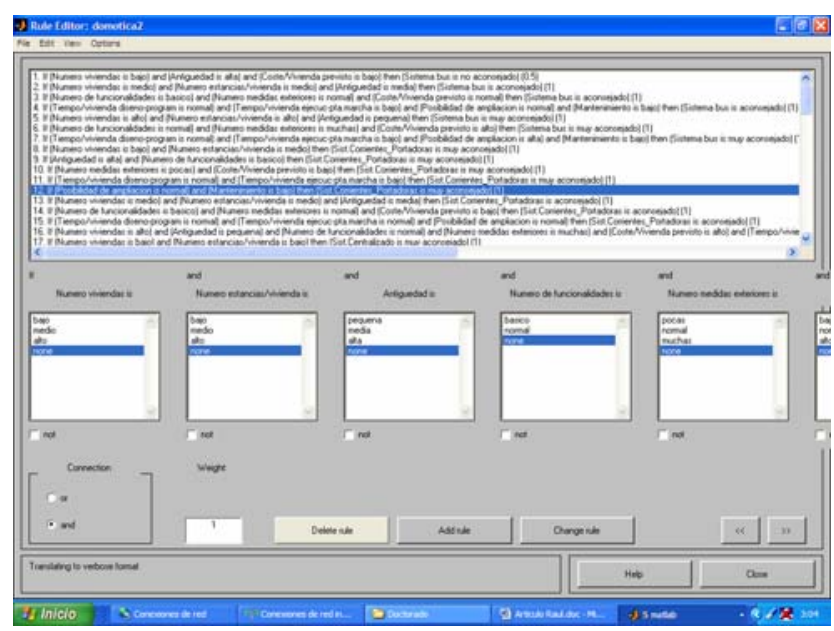

Fig. 5. relationship between the input and the output variables with the "Mandani" method.

The fuzzy model presents 13 input variables, 11 output variables and 79 inference rules. As instance, the rules relating the first output are shown in indexed way; the first 13 columns represent the inputs, the 11 following the outputs, the penultimate one the weight of the rule and the last one indicates the link type between the AND or OR conditions:

Table 6. Rules relating the first output

\begin{tabular}{|c|c|}
\hline \multicolumn{2}{|c|}{ II } \\
\hline 2220000000000,20000000000 & (1) : 1 \\
\hline 0001220000000,20000000000 & (1) : 1 \\
\hline 0000002121000,20000000000 & (1) : 1 \\
\hline 3300000000000,30000000000 & (1) : 1 \\
\hline 3312000000000,30000000000 & (1) : 1 \\
\hline 0000330000000,30000000000 & (1) : 1 \\
\hline 0000002100000,30000000000 & (1) : 1 \\
\hline 0000000031000,30000000000 & (1) : 1 \\
\hline
\end{tabular}

\section{Evaluation of the model}

The developed fuzzy model has been evaluated by applying it on 10 different significant cases, and checking that the results agree with the results obtained after a detailled analysis without the use of the application. The selected 10 cases are:
a. Semidetached house
b. Small building
c. Medium building
d. Big building
e. Rural house
f. Hotel in a city
g. Office building
h. Museum
i. Shopping centre
j. Temple or church

In next subsections, the input data used, the obtained results, and a brief interpretation of them are shown in every case.

\section{A. Semidetached house}

Tables 7 and 8 show the input data used in the developed model, and the output variables obtained. From them, the most suitable system is a decentralized system (0.679) using a PC (0.585) and Internet (0.430) for the development of control and supervision tasks.

Table 7. Input data of a semidetached house

\begin{tabular}{lc} 
number of housings & 1 \\
number of rooms per housing & 5 \\
building age & 3 \\
number of functionalities & 5 \\
number of external measures & 3 \\
estimated cost per housing & 6000 \\
design and planning time & 10 \\
implementation and start-up time & 20 \\
extension possibility & 0.5 \\
maintenance & 0.2 \\
user age & 30 \\
supervision & 0.8 \\
external control of the installation & 0.25 \\
\hline
\end{tabular}

Table 8. Output variables of the semidetached house

\begin{tabular}{ll}
\hline \hline bus system & 0.63472 \\
\hline carrier current system & 0.66590 \\
\hline centralized system & 0.57150 \\
\hline decentralized system & 0.67900 \\
\hline mixed system & 0.63760 \\
\hline preprogramable system & 0.61900 \\
\hline SMS & 0.17380 \\
\hline telephone & 0.17380 \\
\hline Internet & 0.43000 \\
\hline touchscreen & 0.54020 \\
\hline PC & 0.58550 \\
\hline \hline
\end{tabular}

\section{B. Small housing building}

Tables 9 and 10 show the input data used in the developed model, and the output variables obtained. From them, a carrier current system or a decentralized system are equally recommended $(0.727)$, as well as the use of a touchscreen (0.559).

Table 9. Input data of a small housing building number of housings 6 number of rooms per housing 3 building age number of functionalities estimated cost per housing $\quad 2000$ design and planning time 2 implementation and start-up time $\quad 20$ extension possibility $\quad 0.5$ maintenance $\quad 0.2$ user age 35 supervision $\quad 0.2$ external control of the installation $\quad 0.1$ 
Table 10. Output variables of the small housing building

\begin{tabular}{ll}
\hline \hline bus system & 0.55508 \\
\hline carrier current system & 0.72745 \\
\hline centralized system & 0.69894 \\
\hline decentralized system & 0.72745 \\
\hline mixed system & 0.53171 \\
\hline preprogramable system & 0.59198 \\
\hline SMS & 0.26505 \\
\hline telephone & 0.26505 \\
\hline Internet & 0.19688 \\
\hline touchscreen & 0.55866 \\
\hline PC & 0.22839 \\
\hline \hline
\end{tabular}

\section{Medium housing building}

Tables 11 and 12 show the input data used in the developed model, and the output variables obtained. From them, a carrier current system or a decentralized system are equally recommended $(0.624)$, as well as the use of a touchscreen (0.559).

Table 11. Input data of a medium housing building

\begin{tabular}{lc} 
number of housings & 35 \\
number of rooms per housing & 3 \\
building age & 0 \\
number of functionalities & 5 \\
number of external measures & 1 \\
estimated cost per housing & 4000 \\
design and planning time & 6 \\
implementation and start-up time & 20 \\
extension possibility & 0.5 \\
maintenance & 0.1 \\
user age & 35 \\
supervision & 0.1 \\
external control of the installation & 0.1 \\
\hline
\end{tabular}

Table 12. Output variables of the medium housing building

\begin{tabular}{ll}
\hline \hline bus system & 0.60341 \\
\hline carrier current system & 0.62408 \\
\hline centralized system & 0.60474 \\
\hline decentralized system & 0.62408 \\
\hline mixed system & 0.59087 \\
\hline preprogramable system & 0.61787 \\
\hline SMS & 0.52592 \\
\hline telephone & 0.52592 \\
\hline Internet & 0.19688 \\
\hline touchscreen & 0.55866 \\
\hline PC & 0.19688 \\
\hline \hline
\end{tabular}

\section{Big housing building (development)}

Tables 13 and 14 show the input data used in the developed model, and the output variables obtained. From them, the most suitable system is a centralized system (0.853), although a descentralized system is also advisable (0.798). A touchscreen is proposed (0.572) in order to develop the supervisión, and the telephone or SMS systems (0.525) to control the installation from outside.
Table 13. Input data of a

big housing building (development) number of housings 200 number of rooms per housing 2 building age number of functionalities number of external measures estimated cost per housing design and planning time implementation and start-up time 20 extension possibility $\quad 0.5$ maintenance $\quad 0.1$ user age 45 supervision 0.2 external control of the installation $\quad 0.2$

Table 14. Output variables of the big housing building (development)

\begin{tabular}{ll}
\hline \hline bus system & 0.60341 \\
\hline carrier current system & 0.66382 \\
\hline centralized system & 0.85355 \\
\hline decentralized system & 0.79812 \\
\hline mixed system & 0.50008 \\
\hline preprogramable system & 0.61787 \\
\hline SMS & 0.52592 \\
\hline telephone & 0.52592 \\
\hline Internet & 0.19944 \\
\hline touchscreen & 0.57246 \\
\hline PC & 0.19944 \\
\hline \hline
\end{tabular}

\section{E. Rural house}

Tables 15 and 16 show the input data used in the developed model, and the output variables obtained.

Table 15. Input data of a rural house number of buildings 1 number of rooms per building $\quad 10$ building age $\quad 50$ number of functionalities 3 number of external measures $\quad 1$ estimated cost per housing $\quad 2000$ design and planning time $\quad 10$ implementation and start-up time $\quad 15$ extension possibility $\quad 0.2$ maintenance $\quad 0.1$ user age $\quad 50$ supervision $\quad 0.75$ external control of the installation $\quad 0.05$

Table 16. Output variables of the rural house

\begin{tabular}{ll}
\hline \hline bus system & 0.70747 \\
\hline carrier current system & 0.70747 \\
\hline centralized system & 0.84690 \\
\hline decentralized system & 0.68899 \\
\hline mixed system & 0.50070 \\
\hline preprogramable system & 0.56457 \\
\hline SMS & 0.18100 \\
\hline telephone & 0.18100 \\
\hline Internet & 0.19502 \\
\hline touchscreen & 0.50515 \\
\hline PC & 0.54258 \\
\hline \hline
\end{tabular}


From them, the most suitable system is a centralized system (0.847), although bus or carrier current systems are also advisable (0.707). A PC (0.543) and a touchscreen (0.505) are also proposed.

\section{F. Hotel in a city}

Tables 17 and 18 show the input data used in the developed model, and the output variables obtained. From them, the most suitable system is a preprogramable system (0.763) using a PC (0.571) for the development of control and supervision tasks.

Table 17. Input data of a hotel

\begin{tabular}{lc}
\hline \hline number of housings & 100 \\
number of rooms per housing & 2 \\
building age & 0 \\
number of functionalities & 3 \\
number of external measures & 3 \\
estimated cost per housing & 2000 \\
design and planning time & 10 \\
implementation and start-up time & 20 \\
extension possibility & 0.5 \\
maintenance & 0.1 \\
user age & 50 \\
supervision & 0.9 \\
external control of the installation & 0.2 \\
\hline \hline
\end{tabular}

Table 18. Output variables of the hotel

\begin{tabular}{ll}
\hline \hline bus system & 0.61237 \\
\hline carrier current system & 0.62442 \\
\hline centralized system & 0.60341 \\
\hline decentralized system & 0.62260 \\
\hline mixed system & 0.59971 \\
\hline preprogramable system & 0.76281 \\
\hline SMS & 0.15912 \\
\hline telephone & 0.15912 \\
\hline Internet & 0.19680 \\
\hline touchscreen & 0.50748 \\
\hline PC & 0.57122 \\
\hline \hline
\end{tabular}

\section{G. Office building}

Tables 19 and 20 show the input data used in the developed model, and the output variables obtained.

Table 19. Input data of a office building

\begin{tabular}{lc} 
number of offices & 40 \\
number of rooms per office & 6 \\
building age & 0 \\
number of functionalities & 4 \\
number of external measures & 2 \\
estimated cost per housing & 6000 \\
design and planning time & 10 \\
implementation and start-up time & 10 \\
extension possibility & 0.5 \\
maintenance & 0.25 \\
user age & 35 \\
supervision & 0.5 \\
external control of the installation & 0.01 \\
\hline
\end{tabular}

From them, the most suitable system is a centralized system (0.754), although a preprogramable system is also advisable (0.709). A touchscreen (0.554) and a PC (0.553) are also proposed.

\section{H. Museum}

Tables 21 and 22 show the input data used in the developed model, and the output variables obtained. From them, the most suitable system is a centralized system (0.858), using Internet (0.571) or a PC (0.585) for the development of control and supervision tasks.

Table 21. Input data of a museum number of buildings 1 number of rooms per building $\quad 10$ building age $\quad 60$ number of functionalities 3 number of external measures 2 estimated cost per housing $\quad 6000$ design and planning time 10 implementation and start-up time $\quad 20$ extension possibility $\quad 0.05$ maintenance $\quad 0.15$ user age $\quad 45$ supervision $\quad 0.95$ external control of the installation $\quad 0.75$

Table 22. Output variables of the museum

\begin{tabular}{ll}
\hline \hline bus system & 0.83252 \\
\hline carrier current system & 0.83252 \\
\hline centralized system & 0.85845 \\
\hline decentralized system & 0.66198 \\
\hline mixed system & 0.53330 \\
\hline preprogramable system & 0.52084 \\
\hline SMS & 0.38279 \\
\hline telephone & 0.38279 \\
\hline Internet & 0.57057 \\
\hline touchscreen & 0.50342 \\
\hline PC & 0.58499 \\
\hline \hline
\end{tabular}

\section{Shopping center}

Tables 23 and 24 show the input data used in the developed model, and the output variables obtained. From them, the most suitable system is a preprogramable system (0.717) using a PC (0.554) or a touchscreen 
(0.516) for the development of control and supervision tasks.

Table 23. Input data of a shopping center

number of establishments 50

number of rooms per establishment $\quad 1.5$

building age 5

number of functionalities $\quad 4$

number of external measures 2

estimated cost per housing $\quad 3000$

design and planning time $\quad 10$

implementation and start-up time $\quad 20$

extension possibility $\quad 0.75$

maintenance $\quad 0.01$

user age $\quad 40$

supervision $\quad 0.65$

external control of the installation $\quad 0.05$

Table 24. Output variables of the shopping center

\begin{tabular}{ll}
\hline \hline bus system & 0.61537 \\
\hline carrier current system & 0.61537 \\
\hline centralized system & 0.55858 \\
\hline decentralized system & 0.55858 \\
\hline mixed system & 0.65413 \\
\hline preprogramable system & 0.71732 \\
\hline SMS & 0.19131 \\
\hline telephone & 0.19131 \\
\hline Internet & 0.19513 \\
\hline touchscreen & 0.51558 \\
\hline PC & 0.55382 \\
\hline \hline
\end{tabular}

\section{J. Temple or church}

Tables 25 and 26 show the input data used in the developed model, and the output variables obtained. From them, the most suitable system is a centralized system (0.867), although bus or carrier current systems are also advisable (0.814), as well as telephone or SMS systems (0.547) in order to control the installation from outside.

Table 25. Input data of a temple or church number of buildings 1 number of rooms per housing 6 building age

number of functionalities

number of external measures

estimated cost per housing

6000

design and planning time

10

implementation and start-up time $\quad 30$

extension possibility $\quad 0.05$

maintenance $\quad 0.05$

user age $\quad 60$

supervision $\quad 0.01$

external control of the installation $\quad 0.05$
Table 26. Output variables of the temple or church

\begin{tabular}{ll}
\hline \hline bus system & 0.81449 \\
\hline carrier current system & 0.81449 \\
\hline centralized system & 0.86689 \\
\hline decentralized system & 0.77579 \\
\hline mixed system & 0.52203 \\
\hline preprogramable system & 0.50556 \\
\hline SMS & 0.54707 \\
\hline telephone & 0.54707 \\
\hline Internet & 0.19401 \\
\hline touchscreen & 0.41360 \\
\hline PC & 0.19401 \\
\hline \hline
\end{tabular}

\section{Conclusions}

A fuzzy model has been developed in order to allow deciding and quantifying the best system to use in an domotics or inmotics installation. The model has been developed and validated with the Matlab fuzzy logic toolbox, and has been tested with 10 significant cases based on different types of buildings and housings, obtaining the expected results. We are working in order to improve the factors to considered as input, as well as the inference rules, which constitute the "intelligence" in the calculation of the output variable values, the results.

\section{Acknowledgement}

This paper has been partially supported by the project DPI2007-66679 from the Spanish Education and Science Ministry, and by the University of La Rioja.

\section{References}

[1] Guía Técnica de Aplicación del REBT, GUIA-BT-51 "Instalaciones de Sistemas de Automatización Gestión Técnica de la Energía y Seguridad para Viviendas y Edificios” (2007). Ministerio de Industria, Turismo y Comercio.

[2] Huidobro Moya, J.M. y Millán Tejedor, R.J. (2004). Domótica Edificios Inteligentes. Ed. Creaciones Copyright.

[3] Romero Morales, C., Vázquez Serrano, F., de Castro Lozano C., Domótica e Inmotica. (2004). Ed. Rama

[4] Fernández-Valdivielso, C., Castells, I., Gutierrez, M.A., Matías, I.R. y López-Amo M. Herramientas Software para el Control de Instalaciones Domóticas con bus EIB. (2000) XV Simposium Nacional de la Unión Científica Internacional de Radio pp. 243-244.

[5] Fernández-Valdivielso, C., Matías, I.R., López-Amo, M., La domótica. Esencia de un edificio inteligente (1999), Mundo Electrónico, pp. 56-90. 